\title{
Review Article \\ Involvement of the Gut Chemosensory System in the Regulation of Colonic Anion Secretion
}

\author{
A. Kuwahara \\ Laboratory of Physiology, School of Food and Nutritional Sciences/Graduate Division of Nutritional and Environmental Sciences, \\ University of Shizuoka, Shizuoka, 422-8526, Japan \\ Correspondence should be addressed to A. Kuwahara; kuwahara@u-shizuoka-ken.ac.jp
}

Received 29 August 2014; Accepted 9 September 2014

Academic Editor: Yoshinori Marunaka

Copyright (C) 2015 A. Kuwahara. This is an open access article distributed under the Creative Commons Attribution License, which permits unrestricted use, distribution, and reproduction in any medium, provided the original work is properly cited.

\begin{abstract}
The primary function of the gastrointestinal (GI) tract is the extraction of nutrients from the diet. Therefore, the GI tract must possess an efficient surveillance system that continuously monitors the luminal content for beneficial or harmful compounds. Recent studies have shown that specialized cells in the intestinal lining can sense changes in this content. These changes directly influence fundamental GI processes such as secretion, motility, and local blood flow via hormonal and/or neuronal pathways. Until recently, most studies examining the control of ion transport in the colon have focused on neural and hormonal regulation. However, study of the regulation of gut function by the gut chemosensory system has become increasingly important, as failure of this system causes dysfunctions in host homeostasis, as well as functional GI disorders. Furthermore, regulation of ion transport in the colon is critical for host defense and for electrolytes balance. This review discusses the role of the gut chemosensory system in epithelial transport, with a particular emphasis on the colon.
\end{abstract}

\section{Introduction}

The primary function of the gastrointestinal (GI) tract is obtaining energy sources from the diet as nutrients. Under physiological conditions, approximately $8 \mathrm{~L}$ of fluid is secreted into the small intestine per day. However, the majority of the secreted fluid ( $\sim 6-7 \mathrm{~L} /$ day in humans) is reabsorbed in the small intestine, with approximately $1.5 \mathrm{~L}$ of chyme normally passed through the ileocecal valve into the large intestine daily [1]. Less than $100 \mathrm{~mL}$ of fluid is excreted outside the body with the feces. The main functions of the colon are the salvage of the remaining fluid and electrolytes entering from the small intestine and the dehydration and storage of feces. However, colonic epithelia are also able to secrete fluid as a host defense mechanism.

In the colon, approximately 100 trillion bacteria, termed the gut microbiota, are present in the lumen. Gut microbiota continuously produces large quantities of bioactive chemicals that can be beneficial or harmful to the host, as confirmed by analysis of the microbiota genome. Such analysis estimated that gut microbiota contains 150 -fold more genes than does the host genome [2]. These bioactive chemicals have a profound influence on many aspects of human health, as gut microbiota are able to produce harmful substances, in addition to those that are beneficial. For example, bacterial fermentation of indigestible carbohydrates produces shortchain fatty acids (SCFAs), which can affect various GI functions including ion transport and motility. These SCFAs can be absorbed by the colonic mucosa as energy sources [3]. On the other hand, bile acids entering the colon can be metabolized by microbiota; thus, primary bile acids are converted to secondary bile acids [4]. Secondary bile acids can subsequently promote the development of GI malignancies [5]. Therefore, the colon must be able to discriminate between beneficial and deleterious substances.

One of the more important host-defense mechanisms of the colon is the ability to flush out harmful substances via fluid secretion, mainly through $\mathrm{Cl}^{-}$secretion. Indeed, the colon is able to adapt to extreme changes in electrolyte flow such as those during severe secretory or reabsorptive states $[1,6]$. Under physiological conditions, there is net colonic absorption of $\mathrm{Na}^{+}$and $\mathrm{Cl}^{-}$in the colon. The mechanism underlying colonic $\mathrm{Cl}^{-}$secretion is well understood and includes the following components: the luminal cystic fibrosis 
transmembrane conductance regulator (CFTR), which is a $\mathrm{Cl}^{-}$channel that is activated by cAMP; basolateral $\mathrm{Cl}^{-}$ uptake via a $\mathrm{Na}^{+}-\mathrm{K}^{+}-2 \mathrm{Cl}^{-}$cotransporter (NKCC1); and $\mathrm{Ca}^{2+}{ }_{-}$ activated basolateral $\mathrm{K}^{+}$channels that recycle $\mathrm{K}^{+}$and provide the driving force for $\mathrm{Cl}^{-}$secretion. The secretion of $\mathrm{Cl}^{-}$into the colonic lumen, followed by a paracellular flux of $\mathrm{Na}^{+}$, induces fluid secretion via an osmotic gradient. The energy for active $\mathrm{Cl}^{-}$transport is provided by the action of $\mathrm{Na}^{+}-\mathrm{K}^{+}$ ATPase. Physiological or pathophysiological stimuli of $\mathrm{Cl}^{-}$ secretion act on one or more of these components. In essence, switching between absorption and secretion is controlled by the enteric nervous system (ENS) and by a large number of hormones that usually bind to their respective receptors on the basolateral membrane. In addition to these control systems, recent studies have shown that luminal bioactive substances produced by gut microbiota, including SCFAs, affect epithelial ion transport through the gut chemosensory system [7-9].

The presence of a gut chemosensory system is evident. The same taste transduction molecules that are found in the taste buds of lingual papillae, such as $\alpha$-gustducin, are present in the human and rodent intestinal mucosa $[10,11]$. Accordingly, mRNA expression of taste receptor type 1 (T1R) and type 2 (T2R) families in human and rodent GI tracts has been reported [12]. Therefore, the gut chemosensory system has important roles in controlling GI functions including ion transport. However, the contribution of the gut chemosensory system to the regulation of colonic ion transport is not well understood.

This review aims to provide an overview of the involvement of the gut chemosensory system in colonic ion transport and its mechanisms.

\section{SCFA Receptors}

SCFAs are the predominant anions in the content of the large intestine, existing at concentration of $\sim 100 \mathrm{mM}$ and mainly consisting of acetate, propionate, and butyrate. They are produced by bacterial fermentation of specific indigestible dietary fibers and oligosaccharides that are not absorbed in the upper GI tract. SCFAs produced in the large intestine are known to affect a variety of physiological and pathophysiological functions; luminal SCFAs are not only absorbed as nutrients across the intestinal epithelia, but also utilized as chemical signals that influence epithelial proliferation [13], mesenteric blood flow [14], colonic motility [15], and colonic ion transport $[16,17]$. For example, luminal application of propionate and butyrate, but not acetate, in the colon has been reported to induce epithelial $\mathrm{Cl}^{-} / \mathrm{HCO}_{3}{ }^{-}$secretion via both neural and nonneural mechanisms $[16,17]$. On the other hand, serosal application of propionate and other SCFAs did not elicit $\mathrm{Cl}^{-}$secretion [17]. These results suggest that luminal SCFAs are detected by certain chemosensory systems located in the colonic epithelial layer. Until recently, the mechanism by which luminal SCFAs are detected in the intestinal mucosa and the implications of the SCFA-induced secretory response were unclear.

In 2003, two orphan G-protein coupled receptors, FFA2 (GPR43) and FFA3 (GPR41), were discovered to be receptors for SCFA [18-20]. These two receptors share $\sim 40 \%$ amino acid sequence similarity and remain conserved across several mammalian species. They differ in their affinity for SCFAs, their tissue distribution, and their physiological roles. FFA2 has similar affinities for acetate, propionate, and butyrate, whereas FFA3 differs in affinities according to the sequence propionate $>$ butyrate $\gg$ acetate. Thus, acetate preferentially activates FFA2, propionate primarily activates FFA3, and butyrate activates both FFA 2 and FFA 3 equally.

FFR2 and FFR3 have distinct G-protein-couples in their intracellular signaling cascades, FFA2 couples to both pertussis toxin-sensitive $\left(G_{i / o}\right)$ and -insensitive $\left(G_{q}\right)$ G protein whereas FFA3 only couples to $G_{i / o}$ protein. We have recently demonstrated that colonic epithelia, particularly, peptide YY and glucagon-like peptide 1- (GLP-1-) containing Ltype enteroendocrine cells in humans [21], guinea-pigs [16], and rats [22], express two SCFA receptors, FFA2 and FFA3. Our morphological data suggest that SCFA receptors located on colonic epithelial cells can detect luminal SCFA, thus eliciting secretory responses through neural and nonneural mechanisms.

Segmental heterogeneity of electrolyte transport in the colon has also been previously observed in humans and other species $[16,17,23]$. In the case of SCFAs, propionate and butyrate, but not acetate, induce $\mathrm{Cl}^{-} / \mathrm{HCO}_{3}{ }^{-}$secretion in the rectum, as well as in the distal and middle colon. On the other hand, propionate and butyrate do not stimulate $\mathrm{Cl}^{-} / \mathrm{HCO}_{3}{ }^{-}$ secretion in the proximal colon. This regional difference in the secretory responses to luminal propionate can be explained by the regional difference in the acetylcholine (ACh) content and its release in the proximal and distal colon [24].

Luminal application of propionate in the distal colon induces $\mathrm{Cl}^{-} / \mathrm{HCO}_{3}{ }^{-}$secretion, and pretreatment of the mucosal surface with procaine or superficial mucosal damage with hypertonic sodium sulfate or xylose inhibits the propionate-induced secretion by $90 \%$ [17, 24]. Therefore, propionate-induced $\mathrm{Cl}^{-} / \mathrm{HCO}_{3}{ }^{-}$secretion is caused by the activation of SCFA receptors located on mucosal epithelial cells.

Neural blockade with tetrodotoxin (TTX) inhibits the propionate-induced $\mathrm{Cl}^{-} / \mathrm{HCO}_{3}{ }^{-}$secretion by $40 \%$ compared with the control, whereas atropine and local anesthesia remarkably reduce propionate-induced responses by $81-90 \%$ and $76-82 \%$, respectively $[17,24]$. Furthermore, propionateinduced $\mathrm{Cl}^{-} / \mathrm{HCO}_{3}{ }^{-}$secretion is not affected by tachyphylaxis, calcitonin gene-related peptide, 5-hydroxytryptamine (5-HT), histamine, neurotensin, or substance P [25]. The GI tract is densely innervated by cholinergic neurons, and $\mathrm{Cl}^{-} / \mathrm{HCO}_{3}{ }^{-}$secretion is induced by activation of muscarinic receptors located on colonic epithelial cells $[26,27]$. These observations suggest that SCFA-induced $\mathrm{Cl}^{-} / \mathrm{HCO}_{3}{ }^{-}$secretion is linked to ENS, with involvement of cholinergic secretomotor neurons and nonneural release of ACh.

Recently, Yajima et al. showed that ACh is released from the basolateral side of the distal colon by luminal chemical stimulation with SCFA concomitant with propionateinduced $\mathrm{Cl}^{-} / \mathrm{HCO}_{3}{ }^{-}$secretion [24]. Therefore, the remaining $50 \%$ of propionate-induced $\mathrm{Cl}^{-} / \mathrm{HCO}_{3}{ }^{-}$secretion may be 
due to the release of ACh from the epithelial cells into the basolateral side. In the same study, Yajima et al., showed that prior addition of luminal $3-\mathrm{Cl}^{-}$propionate completely blocked the short-circuit current $\left(I_{\mathrm{sc}}\right)$ response and abolished ACh release in response to luminal propionate. They concluded from the results that ACh-storing epithelial cells have a receptor for propionate although further studies are necessary to identify specific cell that store ACh. Therefore, ACh release stimulated by FFAs may affect $\mathrm{Cl}^{-} / \mathrm{HCO}_{3}{ }^{-}$ secretion by autocrine fashion (Figure 1).

With respect to the involvement of SCFA receptors, FFA3 may be involved in the secretory process since acetate, the preferred ligand of FFA2, has no effect on mucosal $\mathrm{Cl}^{-} / \mathrm{HCO}_{3}{ }^{-}$secretion in distal colon of rats [17]. Unfortunately, the intracellular molecular pathways underlying the effects of SCFAs on colonic $\mathrm{Cl}^{-} / \mathrm{HCO}_{3}{ }^{-}$secretion are still not fully understood. Therefore, further study is needed to identify the molecular pathways of FFA-stimulated ion transport in the colon.

Indigestible dietary fibers are fermented in the cecum and in the proximal colon by anaerobic microbiota, as mentioned previously. Most bacterial activity occurs in the cecum and in the proximal colon, where substrate availability is highest, with the availability of substrates declining toward the distal colon [28]. Therefore, the proximal colon is continuously exposed to high concentrations of SCFAs, which decrease from the proximal colon to distal colon. However, the proximal colon does not secrete $\mathrm{Cl}^{-} / \mathrm{HCO}_{3}{ }^{-}$ in response to SCFAs, as mentioned above. On the other hand, the distal colonic mucosa is exposed to SCFAs when semisolid contents containing SCFAs are transported to the distal colon. Therefore, detection of SCFAs is important in the distal colon as it has ability to secrete $\mathrm{Cl}^{-} / \mathrm{HCO}_{3}{ }^{-}$after SCFA stimulation.

In combination with the contractile response, the secretory response to luminal SCFAs in the distal colon seems to function as a lubricant for the movement of luminal contents in the colon. Furthermore, the distal colon and rectum are a boundary between the host and external environment; thus, the high secretory ability of the distal colon is physiologically important for host defense, as it needs to flush out harmful agents, in addition to finalizing electrolyte tuning.

\section{Bitter Taste Receptors}

In recent years, numerous studies have suggested the presence of taste receptors and taste-associated signaling components in the GI tract, in addition to their presence in the gustatory system [29]. The discovery of taste-associated molecules in the GI tract has led to the hypothesis that taste receptors are a part of the gut chemosensory system that recognizes nutrients and chemicals, which enter the GI tract (e.g., FFA2 and FFA3), and trigger various physiological processes [30]. The bitter taste, one of the five basic tastes, is mediated by bitter taste receptors (T2Rs). The bitter taste signal is a "notifier" of toxic substances, allowing the host to avoid harm [31]. Genomic sequencing analysis has identified the T2R family as a receptor family specific to bitter

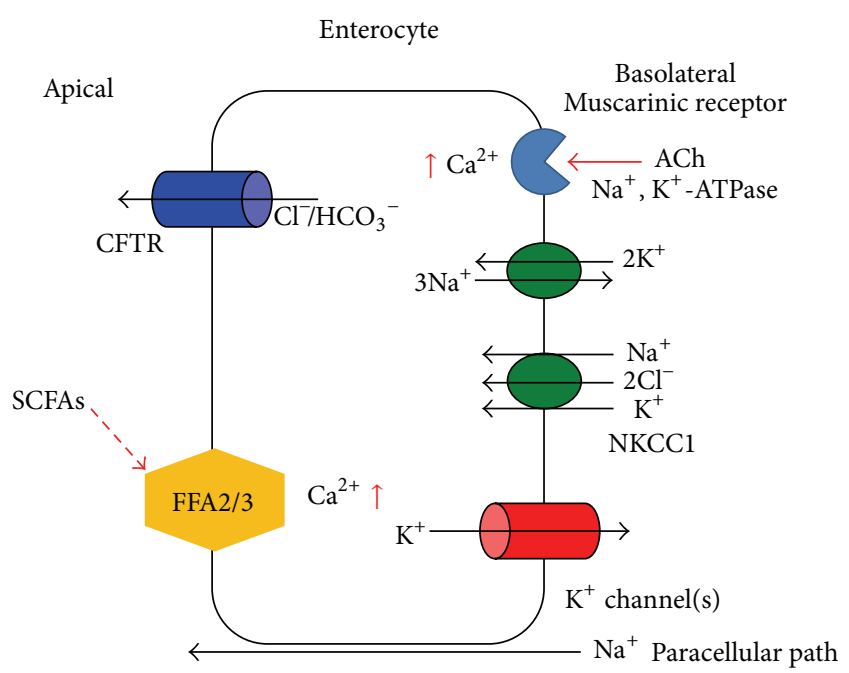

FIgURE 1: Schematic diagram of $\mathrm{Cl}^{-}$secretion stimulated by shortchain fatty acids in colonic epithelial cells. At the basolateral membrane, $\mathrm{Cl}^{-}$enters the cell from the basolateral space across the $\mathrm{Na}^{+}$, $\mathrm{K}^{+}-2 \mathrm{Cl}^{-}$cotransporter (NKCCl). $\mathrm{Na}^{+}, \mathrm{K}^{+}$-ATPase causes drainage of $\mathrm{Na}^{+}$, and $\mathrm{K}^{+}$leaves via the $\mathrm{K}^{+}$channel. $\mathrm{Na}^{+}$also moves to the apical side paracellularly. The cystic fibrosis transmembrane conductance regulator (CFTR), which is located on the apical membrane, allows $\mathrm{Cl}^{-}$to exit the cell. The colonic epithelium CFTR $\mathrm{Cl}^{-}$ conductance is constitutively active [1]. Luminal SCFAs stimulate the FFA2/3 receptors located on the apical membrane, which in turn activate second messenger pathways to induce ACh release from epithelial cells basolaterally. The released ACh activates muscarinic receptors located on the basolateral membrane of epithelial cells, inducing $\mathrm{Cl}^{-}$secretion.

tastants, consisting of $\sim 30$ members in humans and rodents [32-35].

The $\alpha$-subunit of the taste-specific $\mathrm{G}$ protein gustducin is expressed in the GI mucosa of humans and rodents $[10,11,36$, 37]. Unlike FFA2- and FFA3-expressing cells, cells expressing the bitter receptor have not been identified. Several studies in model cell lines [38, 39] and a histochemical study using an antibody raised against mouse T2R138 suggested that enteroendocrine cells express putative bitter taste receptor [40]. However, another study has recently shown that a subset of mouse colonic goblet cells also express the bitter taste receptor T2R131 [41]. Since goblet cells produce mucus to protect intestinal epithelia [42,43], T2R-expressing cells may contribute defense-related functions involving the recognition of harmful bioactive chemicals.

Recently, we have shown that, in mucosa-submucosa preparations mounted in Ussing chambers, the mucosal application of 6- $n$-propyl-2-thiouracil (6-PTU) at concentrations greater than $10^{-4} \mathrm{M}$ increased $I_{\mathrm{sc}}$ in both human and rat colons in a concentration-dependent manner [7]. Multiple T2R family members (at least T2R-1, -4 , and -38) in humans are known to detect 6-PTU [34, 44, 45], and these genes are the most conserved between humans and rodents [12]. Previous human taste-test studies and briefaccess mouse studies have also shown that the minimal effective concentration of 6 -PTU is $\sim 10^{-4} \mathrm{M}[31,46,47]$. 
Therefore, the threshold for 6-PTU in T2R-expressing cells in the colon in both humans and rats is similar to that in gustatory senses. After the addition of 6-PTU, the base line $I_{\text {sc }}$ gradually increased and reached a plateau over 10-15 min, which continued for $>20 \mathrm{~min}$ [7]. The increase in $I_{\text {sc }}$ induced by 6-PTU was reduced by bumetanide $\left(10^{-4} \mathrm{M}\right)$, an inhibitor of NKCC1, to $69 \%$ of the control, whereas NPPB $\left(10^{-4} \mathrm{M}\right)$, an inhibitor of the CFTR, almost completely abolished the 6PTU-induced increase in $I_{\mathrm{sc}}$. NPPB-sensitive $\mathrm{Cl}^{-}$channel, for example, CFTRs located at the apical membrane, also secretes $\mathrm{HCO}_{3}{ }^{-}$[1]. Thus, the 6-PTU-induced increase in $I_{\mathrm{sc}}$ is due to secretion of $\mathrm{Cl}^{-}$and $\mathrm{HCO}_{3}{ }^{-}$. This is further supported by the observation that the 6-PTU-induced $I_{\mathrm{sc}}$ response is almost completely abolished in $\mathrm{Cl}^{-} / \mathrm{HCO}_{3}{ }^{-}$-free solution [7].

The 6-PTU response elicited is reduced by piroxicam, a nonselective COX inhibitor, and NS-398, a COX2 inhibitor, but is not affected by TTX. Therefore, 6-PTUstimulated anion secretion is thought to be involved in prostaglandin (PG) synthesis [7]. Furthermore, exogenous addition of prostaglandin $\mathrm{E}_{2}\left(\mathrm{PGE}_{2}\right)$ enhances 6-PTUinduced $I_{\mathrm{sc}}$ response in the presence of piroxicam in a concentration-dependent manner [7], indicating that the 6PTU-induced increase in $I_{\mathrm{sc}}$ may be amplified when the concentration of extracellular $\mathrm{PGE}_{2}$ in the colon is elevated, for example, during inflammation. The $\mathrm{PGE}_{2}$ concentration in the intestine can be increased by mechanical stimulation [48] or inflammation $[49,50]$, with $\mathrm{PGE}_{2}$ concentrations over $10^{-7} \mathrm{M}$ considered pathophysiological [51]. Therefore, the 6PTU-induced fluid secretion in the presence of high $\mathrm{PGE}_{2}$ concentrations is considered to be a host defense mechanism to flush out noxious substances from the colonic lumen, during, for instance, inflammation.

$\mathrm{PGE}_{2}$ is known to increase the concentration of intracellular cAMP in colonic epithelial cells [52]. It has also been reported that STC-1, a mouse enteroendocrine cell line, expresses T2R mRNA and that $10^{-3} \mathrm{M}$ 6-PTU increases the intracellular $\mathrm{Ca}^{2+}$ concentration $\left(\left[\mathrm{Ca}^{2+}\right]_{i}\right)[12]$. These results raise the possibility that bitter tastants (including 6-PTU) that induce an increase in $\left[\mathrm{Ca}^{2+}\right]_{i}$ in colonic epithelia and that elicit $\mathrm{Cl}^{-} / \mathrm{HCO}_{3}{ }^{-}$secretion do so via interactions with PGs (Figure 2).

The mRNA expression of human T2R-1, T2R-4, and T2R38 , as well as orthologous rat T2R-1, T2R-16, and T2R-26, is detected in the colonic mucosa by real-time PCR (RT-PCR) [7]. Although which specific receptor responds to 6-PTU has not been determined, many members of the T2R family that can detect 6-PTU are expressed in the colon [11]. These results suggest that 6-PTU may be detected by colonic epithelial $\mathrm{T} 2 \mathrm{R}$ in both humans and rats, although the precise cellular localization of T2R is currently unknown.

With respect to its physiological significance, bitter tastant-induced anion secretion in the colon is considered an important mechanism to flush out noxious agents from the colonic lumen. For example, bitter compounds that enter the large intestine under normal conditions are most frequently bile acids and their bacterial metabolites. As secondary bile acids promote tumors [53], bitter sensing in the large intestine may be a necessary mechanism for host defense.

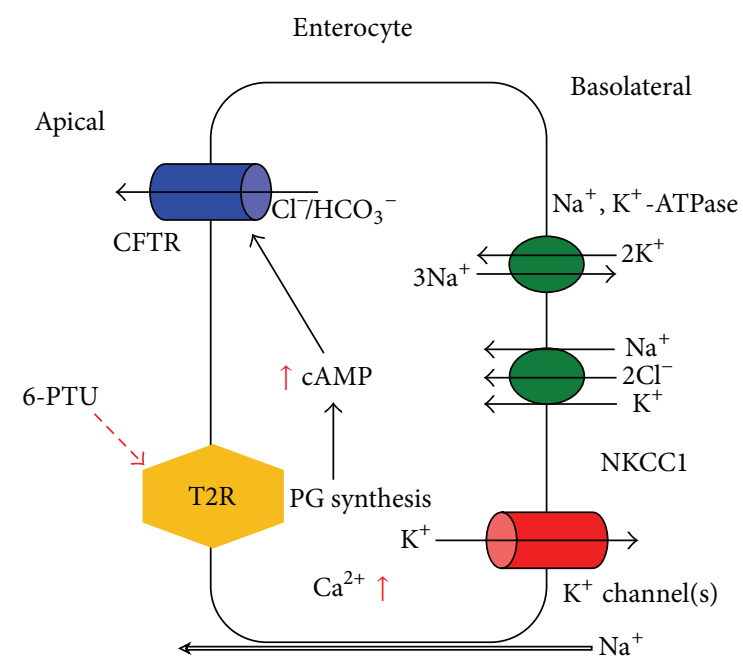

FIGURE 2: Schematic diagram of $\mathrm{Cl}^{-}$secretion stimulated by a bitter tastant (6-PTU) in colonic epithelial cells. Activation of apical T2R by luminal bitter tastant results in the synthesis of prostaglandin. This prostaglandin then induces an increase in intracellular cAMP concentration $\left([\mathrm{cAMP}]_{i}\right)$. Elevated $[\mathrm{cAMP}]_{i}$ activates the CFTR $\mathrm{Cl}^{-}$channels to mediate $\mathrm{Cl}^{-} / \mathrm{HCO}_{3}{ }^{-}$secretion. Activation of T2R simultaneously causes an increase in $\left[\mathrm{Ca}^{2+}\right]_{i}$. The elevated $\left[\mathrm{Ca}^{2+}\right]_{i}$ modulates the $\mathrm{Ca}^{2+}$-activated basolateral $\mathrm{K}^{+}$channels, providing a driving force for the exit of $\mathrm{Cl}^{-} / \mathrm{HCO}_{3}{ }^{-}$.

\section{Odorant Receptor (OR)}

The colonic mucosa of both humans and rats express OR mRNA, and luminal odorants induce 5-HT secretion in isolated duodenal enterochromaffin (EC) cells and in EC cell lines $[54,55]$. Thymol, a major odor constituent of edible herbs that is used in oral care products, activates certain types of the apical odorant receptor (OR1G1). Specifically, it activates class II (the terrestrial-type OR group) but not class I (the fish-like OR group) OR1G1 [56]. Since bacteria have the capacity to synthesize isoprene units and terpenoid biosynthesis enzymes $[57,58]$, active odor molecules may be produced in the mammalian colon. Indeed, a great variety of volatile compounds (including acids, alcohols, aldehydes, and terpenoids) are detected in human feces [59]. It has been reported that the concentration range of fecal indole is $0.5-$ $1 \mathrm{mM}$ in healthy men $[60,61]$. Therefore, the monitoring of volatile compounds in the colonic lumen is critical for host defense.

Recently, we showed that mucosal addition of thymol $\left(10^{-3} \mathrm{M}\right)$ induces $\mathrm{Cl}^{-}$and $\mathrm{HCO}_{3}^{-}$secretion in a concentration-dependent manner in both the human and rat colon [8]. Addition of TTX $\left(10^{-6} \mathrm{M}\right)$ or piroxicam $\left(10^{-5} \mathrm{M}\right)$ did not affect this response, suggesting that thymol-induced anion secretion is independent of the neural and PG synthesis pathways. This differs from stimulation of the bitter taste receptor; thus, there are distinct mechanisms for detecting tastants in the colonic mucosa. It has been reported that odorant stimulation leads to an increase in $\left[\mathrm{Ca}^{2+}\right]_{i}$ in olfactory neurons and in other OR-expressing cells, depending on extracellular $\mathrm{Ca}^{2+}[54,62,63]$. Thymol-induced electrogenic 


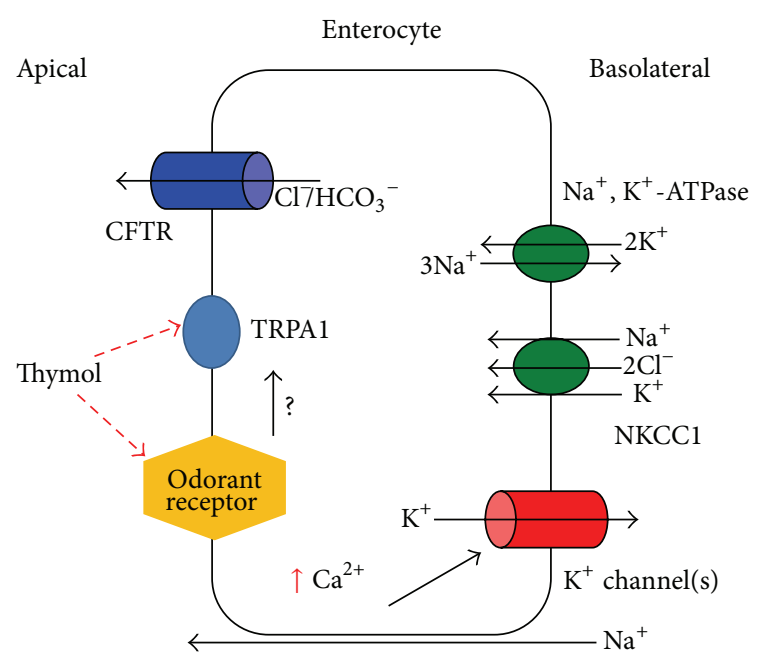

FIGURE 3: Schematic diagram of $\mathrm{Cl}^{-}$secretion stimulated by an odor tastant (thymol) in colonic epithelial cells. Activation of OR1G1 by luminal thymol increases $\left[\mathrm{Ca}^{2+}\right]_{i}$. The elevated $\left[\mathrm{Ca}^{2+}\right]_{i}$ may modulate $\mathrm{Ca}^{2+}$-activated basolateral $\mathrm{K}^{+}$channels, providing a driving force for the exit of $\mathrm{Cl}^{-} / \mathrm{HCO}_{3}{ }^{-}$. Activation of OR1G1 may also activate TRPAl although it is still unclear whether ORs are linked to TRPA1.

anion secretion is also abolished under $\mathrm{Ca}^{2+}$-free conditions [8]. These results suggest that extracellular $\mathrm{Ca}^{2+}$ is required to elicit thymol-induced anion secretion in the large intestine (Figure 3).

Thymol-induced anion secretion in the distal colon is reduced by HC-030031, a transient receptor potential A1 (TRPA1) blocker. Furthermore, TRPA1 mRNA is detected in the isolated mucosa of humans and rats $[8,64]$. Several odor molecules, particularly those present in spices, are known ligands of not only GPCRs, but also the transient receptor potential (TRP) channel. Thymol activates transient receptor potential vanilloid 3 (TRPV3) and TRPA1 in a cellexpression system $[65,66]$. In the GI tract, it has been reported that TRPA1 activity is involved in the motility of the small intestine [67]. Together, these results suggest that thymol-induced electrogenic anion secretion is mediated via the TRPAl channel. In addition, thymol has been reported to affect luminal SCFA-induced ion secretion. Propionateinduced increases in $I_{\mathrm{sc}}$ are almost completely abolished by pretreatment of tissues with thymol [8]. Therefore, the physiological effects of luminal SCFAs in the large intestine are likely to be modulated by luminal odorant chemicals.

Pretreatment of tissues with bumetanide or $\mathrm{Cl}^{-}$free solution attenuated the thymol-induced increase in $I_{\text {sc }}$. Consistent with other studies, the absence of $\mathrm{HCO}_{3}{ }^{-}$and $\mathrm{Cl}^{-}$ completely suppressed the $I_{\mathrm{sc}}$ response to thymol. Together, these results indicate that the thymol-induced increase in $I_{\mathrm{sc}}$ involves electrogenic $\mathrm{Cl}^{-}$and $\mathrm{HCO}_{3}{ }^{-}$secretion in a NKCC1dependent manner.

It has been reported that thymol-induced electrogenic anion secretion is mediated by the cholinergic neural pathway in the porcine small intestine [68]. However, the mechanisms of thymol-induced secretion are likely different in the small and large intestine as thymol-induced anion secretion is not blocked by TTX in the rat or human large intestine [8]. This discrepancy may be attributed to the following reasons. First, thymol-induced anion secretion in the small intestine is involved in the release of 5-HT because duodenal EC cells release 5-HT after OR stimulation [54, 55]. Second, thymolinduced anion secretion is not blocked by $5-\mathrm{HT}_{3}$ and $5-\mathrm{HT}_{4}$ receptor antagonists in the large intestine [8]. Therefore, luminal thymol-induced anion secretion in the large intestine is mediated by nonneural and nonserotonergic pathways in rats and in humans.

As bacteria can synthesize isoprene units [57], production of active odor molecules similar to thymol may be possible in the mammalian colon. Thus, colonic mucosa may be exposed to high concentrations of various volatile odorants. Because irritant odors, similar to bitter tastants, are danger signals for animals, ORs can play an important role in the luminal surface of the colon in host defense. Although a RT-PCR experiment showed that OR1G1 and TRPAl are present in both human and rat colonic mucosa [8], colonic epithelia consist of many different cell types, including absorptive, goblet, enteroendocrine, and caveolated cells. Therefore, studies should be done to identify the specific sensor cells expressing ORs and TRPA1. At present, it is still unclear whether OR1G1 is directly involved in thymol-induced anion secretion and whether ORs are linked to TRPA1.

\section{TRP Channels}

The TRP channel member, TRPA1 (also known as ANKTM1), was first identified as a cold-sensitive cation channel in murine sensory neurons and is thought to have a role in nociception [69]. Since multiple environmental irritants can activate TRPA1, TRPA1 functions as a chemosensor in nociceptive neurons [70], in the rat urinary bladder [71], and in human keratinocytes [72]. Endogenous inflammatory mediators can also activate TRPA1 [73-75].

To date, 28 mammalian TRP channels have been cloned and characterized. They are grouped into six subfamilies on the basis of their amino acid sequence homology, namely, TRP ankyrin (TRPA), TRP canonical (TRPC), TRP melastatin (TRPM), TRP mucolipin (TRPML), TRP polycystin (TRPP), and TRP vanilloid (TRPV). TRPAl expression in the colon has been demonstrated in humans, mice, rats, and dogs by northern blot analysis and by RT-PCR [64, 76-78]. As described in the section Odorant Receptor, luminal thymol-induced anion secretion involves TRPA1. The function of TRPA1 in the transepithelial ion transport system was examined using a potent TRPA1 agonist allyl isothiocyanate (AITC) [9].

In the human and rat distal colon, the addition of AITC $\left(10^{-6}-10^{-3} \mathrm{M}\right)$ to the luminal side induced an increase in $I_{\mathrm{sc}}$ [9]. On the other hand, serosal application of AITC did not elicit an increase in $I_{\text {sc }}$. AITC-induced increases in $I_{\mathrm{sc}}$ are significantly decreased in the absence of $\mathrm{Cl}^{-}$ and are abolished in the absence of both $\mathrm{Cl}^{-}$and $\mathrm{HCO}_{3}{ }^{-}$. Further, NPPB $\left(10^{-4} \mathrm{M}\right)$ and bumetanide $\left(10^{-4} \mathrm{M}\right)$ significantly reduced AITC-induced $I_{\text {sc }}$ increases. These results indicate that transepithelial anion secretion induced by the 


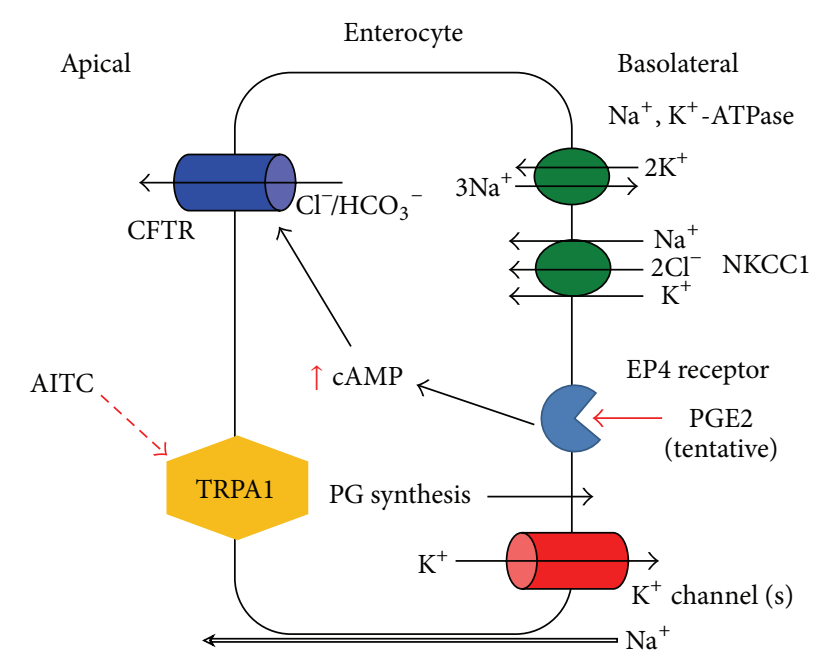

FIGURE 4: Schematic diagram of $\mathrm{Cl}^{-}$secretion stimulated by TRPA1 in colonic epithelial cells. Activation of apical TRPA1 by luminal AITC causes prostaglandins synthesis. The synthesized $\mathrm{PGE}_{2}$ may then be released basolaterally. This released $\mathrm{PGE}_{2}$ may act on $\mathrm{EP}_{4}$ receptors. Activation of the $\mathrm{EP}_{4}$ receptor induces an increase in $[\mathrm{cAMP}]_{i}$ which then activates the CFTR $\mathrm{Cl}^{-}$channels to induce $\mathrm{Cl}^{-} / \mathrm{HCO}_{3}{ }^{-}$secretion.

activation of TRPA1 is dependent on $\mathrm{Cl}^{-}$uptake by NKCC1 and on excretion of $\mathrm{Cl}^{-} / \mathrm{HCO}_{3}{ }^{-}$by $\mathrm{Cl}^{-}$channels at the apical membrane (Figure 4).

In fractions enriched with isolated EC cells from the rat small intestine, 5-HT was released by AITC and cinnamaldehyde [67]. However, in the colon, a $5-\mathrm{HT}_{3}$ antagonist, 3-tropanyl-3, 5-dichlorobenzoate, and a $5-\mathrm{HT}_{4}$ antagonist SB204070 $\left(10^{-5} \mathrm{M}\right)$ did not affect the response to AITC [9]. Furthermore, coapplication of these antagonists abolished the response to the serosal addition of 5-HT $\left(10^{-5} \mathrm{M}\right)$ but did not affect the AITC-induced $I_{\text {sc }}$ response. Serosal application of the TRPA1 blocker HC030031 $\left(10^{-4} \mathrm{M}\right)$ did not affect the response to AITC, whereas mucosal treatment significantly inhibited the AITC-induced increases in $I_{\text {sc }}$. These observations support the hypothesis that TRPAl likely functions on the apical side of colonic epithelia.

COX products are involved in the colonic ion transport system. In particular, $\mathrm{PGE}_{2}$ induces $\mathrm{Cl}^{-}$secretion in the rat colon [79] and enhances the effects of other secretagogues [7]. Mucosal treatment with a COX inhibitor, piroxicam $\left(10^{-5} \mathrm{M}\right)$, decreases the AITC-induced response in the rat and human colon. However, exogenous $\mathrm{PGE}_{2}$ does not enhance AITC-induced anion secretion, even in the absence of the COX inhibitor, suggesting that AITC stimulates $\mathrm{PGE}_{2}$ synthesis [9].

Although the mechanisms by which $\mathrm{PGE}_{2}$ contributes to 6-PTU- and AITC-induced anion secretion differ, $\mathrm{PGE}_{2}$ likely plays important roles in the luminal chemosensory system. The function of $\mathrm{PGE}_{2}$ in the GI tract has been well studied, especially in relation to its receptors, $\mathrm{EP}_{1}, \mathrm{EP}_{2}, \mathrm{EP}_{3}$, and $\mathrm{EP}_{4}$. Only $\mathrm{EP}_{2}$ and $\mathrm{EP}_{4}$, which are coupled to the cAMP pathway, mediate $\mathrm{PGE}_{2}$-induced colonic secretion, but $\mathrm{EP}_{1}$ and $\mathrm{EP}_{3}$ do not, as they are coupled to an intracellular $\mathrm{Ca}^{2+}$ pathway instead [80]. An $\mathrm{EP}_{4}$ selective antagonist (ONOAE3-208) significantly reduced AITC-induced anion secretion, whereas the $\mathrm{EP}_{1 / 2}$ antagonist AH6809 did not affect the response to AITC, indicating that $\mathrm{EP}_{4}$, a $\mathrm{PGE}_{2}$ receptor subtype, is involved in AITC-induced anion secretion in both human and rat colons [9]. As application of AITC to the mucosal bathing solution did not result in the release of $\mathrm{PGE}_{2}$ into the bathing solution, $\mathrm{PGE}_{2}$ produced by epithelial cells might be rapidly used as an autocrine transmitter [9].

Recently, the $\mathrm{EP}_{4}$ receptor has been found on the apical membrane of human and rat colonic epithelia via immunohistochemical techniques [81]. Since both serosal and mucosal pretreatment with ONO-AE3-208 abolished the response to AITC, the precise localization of the $\mathrm{EP}_{4}$ receptor is still unknown. Overall, the evidence clearly indicates that a TRPA1-PGE $-\mathrm{EP}_{4}$ secretory pathway that is independent of the neural reflex exists in both human and rat colonic epithelial cells.

TRPAl-dependent thymol-induced anion secretion requires extracellular $\mathrm{Ca}^{2+}$, as described in the section Odorant Receptor. However, the response to AITC was not altered by the removal of extracellular $\mathrm{Ca}^{2+}[9]$. Therefore, AITC-induced anion secretion is mediated by PG synthesis via a $\mathrm{Ca}^{2+}$ independent process. These conclusions were further confirmed after observations that AITC does not increase $\left[\mathrm{Ca}^{2+}\right]_{i}$ in mouse colonic epithelia [78] and that AITC-induced TRPA1 current does not require extracellular $\mathrm{Ca}^{2+}$ in HEK cells [82]. Overall, TRPA1 activation appears to induce $\mathrm{PGE}_{2}$ synthesis independently of extracellular $\mathrm{Ca}^{2+}$ and can cause anion secretion through the $\mathrm{EP}_{4}$ receptor in colonic epithelia.

TRPA1 mRNA is detected in isolated crypts of the rat colon [9]. Furthermore, tyramide-based in situ hybridization and immunohistochemistry for TRPAl demonstrated that TRPA1-expressing cells are localized to the surface epithelium of the rat colon [9]. Recently, it has been reported that activation of TRPA1 inhibits spontaneous contractions and transit by direct activation of myenteric neurons [83]. Therefore, TRPAl agonist-induced colonic $\mathrm{Cl}^{-}$secretion with inhibition of colonic transient seems to physiologically regulate the movement of luminal content in the colon. In addition, TRPA1 may also play a role in flushing out noxious chemicals via massive fluid secretion.

\section{Conclusion}

As colonic mucosa is continuously exposed to noxious chemicals, including toxic compounds such as bacterial metabolites and the products of oxidative stress, in addition to nutrients, the chemosensory system in the gut is critical for distinguishing the nutrients from the other luminal contents. Therefore, proper fluid secretion in the colon is crucial to flush away noxious chemicals, while maintaining host homeostasis.

Although neural and hormonal involvement in fluid secretion in the colon are well documented, the involvement of the gut chemosensory system in the regulation of colonic ion transport is much less understood. Activation of luminal chemosensory receptors is a primary signal eliciting 
colonic fluid secretion. Gut luminal chemosensing involving FFA2, FFA3, T2R, OR, and TRPA1 may act as a line of defense against noxious agents, preventing the large intestine from being exposed to these agents. Therefore, the gut chemosensory system is important for maintaining luminal homeostasis. A variety of sensory receptors expressed in the colonic mucosa serve important functions, at least in the anion secretory system, which stimulates fluid secretion. However, the specific mechanisms involved in anion secretion induced by the gut chemosensory system are largely unknown. Therefore, more studies are required to define the involvement of the gut chemosensory system in colonic ion transport.

\section{Conflict of Interests}

The author declares that there is no conflict of interests regarding the publication of this paper.

\section{References}

[1] K. Kunzelmann and M. Mall, "Electrolyte transport in the mammalian colon: mechanisms and implications for disease," Physiological Reviews, vol. 82, no. 1, pp. 245-289, 2002.

[2] J. Qin, R. Li, M. Arumugam et al., "A human gut microbial gene catalogue established by metagenomic sequencing," Nature, vol. 464, no. 7285, pp. 59-65, 2010.

[3] I. Kaji, S.-I. Karaki, and A. Kuwahara, "Chemosense for luminal environment in the large intestine," Yakugaku Zasshi, vol. 131, no. 12, pp. 1691-1698, 2011.

[4] H. Ajouz, D. Mukherji, and A. Shamseddine, "Secondary bile acids: an underrecognized cause of colon cancer," World Journal of Surgical Oncology, vol. 12, article 164, 2014.

[5] N. S. Nagathihalli, Y. Beesetty, W. Lee et al., "Novel mechanistic insights into ectodomain shedding of egfr ligands amphiregulin and TGF- $\alpha$ : impact on gastrointestinal cancers driven by secondary bile acids," Cancer Research, vol. 74, no. 7, pp. 20622072, 2014.

[6] M. G. Gareau and K. E. Barrett, "Fluid and electrolyte secretion in the inflamed gut: novel targets for treatment of inflammation-induced diarrhea," Current Opinion in Pharmacology, vol. 13, no. 6, pp. 895-899, 2013.

[7] I. Kaji, S.-I. Karaki, Y. Fukami, M. Terasaki, and A. Kuwahara, "Secretory effects of a luminal bitter tastant and expressions of bitter taste receptors, T2Rs, in the human and rat large intestine," The American Journal of Physiology-Gastrointestinal and Liver Physiology, vol. 296, no. 5, pp. G971-G981, 2009.

[8] I. Kaji, S.-I. Karaki, and A. Kuwahara, "Effects of luminal thymol on epithelial transport in human and rat colon," The American Journal of Physiology-Gastrointestinal and Liver Physiology, vol. 300, no. 6, pp. G1132-G1143, 2011.

[9] I. Kaji, Y. Yasuoka, S.-I. Karaki, and A. Kuwahara, "Activation of TRPA1 by luminal stimuli induces $\mathrm{EP}_{4}$-mediated anion secretion in human and rat colon," The American Journal of Physiology-Gastrointestinal and Liver Physiology, vol. 302, no. 7, pp. G690-G701, 2012.

[10] D. Höfer, B. Püschel, and D. Drenckhahn, "Taste receptor-like cells in the rat gut identified by expression of $\alpha$-gustducin," Proceedings of the National Academy of Sciences of the United States of America, vol. 93, no. 13, pp. 6631-6634, 1996.
[11] N. Rozengurt, S. V. Wu, M. C. Chen, C. Huang, C. Sternini, and E. Rozengurt, "Colocalization of the $\alpha$-subunit of gustducin with PYY and GLP-1 in L cells of human colon," The American Journal of Physiology-Gastrointestinal and Liver Physiology, vol. 291, no. 5, pp. G792-G802, 2006.

[12] S. V. Wu, N. Rozengurt, M. Yang, S. H. Young, J. Sinnett-Smith, and E. Rozengurt, "Expression of bitter taste receptors of the T2R family in the gastrointestinal tract and enteroendocrine STC-1 cells," Proceedings of the National Academy of Sciences of the United States of America, vol. 99, no. 4, pp. 2392-2397, 2002.

[13] T. Sakata, "Effects of short-chain fatty acids on the proliferation of gut epithelial cells in vivo," in Physiology and Clinical Aspects of Short-Chain Fatty Acids, J. H. Cummings, J. L. Rombeau, and T. Sakata, Eds., pp. 289-305, 1999.

[14] G. Knock, D. Psaroudakis, S. Abbot, and P. I. Aaronson, "Propionate-induced relaxation in rat mesenteric arteries: a role for endothelium-derived hyperpolarising factor," Journal of Physiology, vol. 538, no. 3, pp. 879-890, 2002.

[15] R. Mitsui, S. Ono, S. I. Karaki, and A. Kuwahara, "Neural and non-neural mediation of propionate-induced contractile responses in the rat distal colon," Neurogastroenterology o Motility, vol. 17, no. 4, pp. 585-594, 2005.

[16] S. I. Karaki and A. Kuwahara, "Propionate-induced epithelial $\mathrm{K}^{+}$and $\mathrm{Cl}^{-} / \mathrm{HCO}_{3}{ }^{-}$secretion and free fatty acid receptor 2 (FFA2, GPR43) expression in guinea-pig distal colon," European Journal of Physiology, vol. 461, no. 1, pp. 141-152, 2011.

[17] T. Yajima, "Luminal propionate-induced secretory response in the rat distal colon in vitro," Journal of Physiology, vol. 403, pp. 559-575, 1988.

[18] A. J. Brown, S. M. Goldsworthy, A. A. Barnes et al., "The orphan G protein-coupled receptors GPR41 and GPR43 are activated by propionate and other short chain carboxylic acids," The Journal of Biological Chemistry, vol. 278, no. 13, pp. 11312-11319, 2003.

[19] E. le Poul, C. Loison, S. Struyf et al., "Functional characterization of human receptors for short chain fatty acids and their role in polymorphonuclear cell activation," The Journal of Biological Chemistry, vol. 278, no. 28, pp. 25481-25489, 2003.

[20] N. E. Nilsson, K. Kotarsky, C. Owman, and B. Olde, "Identification of a free fatty acid receptor, FFA2R, expressed on leukocytes and activated by short-chain fatty acids," Biochemical and Biophysical Research Communications, vol. 303, no. 4, pp. 1047-1052, 2003.

[21] S.-I. Karaki, H. Tazoe, H. Hayashi et al., "Expression of the short-chain fatty acid receptor, GPR43, in the human colon," Journal of Molecular Histology, vol. 39, no. 2, pp. 135-142, 2008.

[22] S.-I. Karaki, R. Mitsui, H. Hayashi et al., "Short-chain fatty acid receptor, GPR43, is expressed by enteroendocrine cells and mucosal mast cells in rat intestine," Cell and Tissue Research, vol. 324, no. 3, pp. 353-360, 2006.

[23] J. H. Park, P.-L. Rhee, J. H. Lee et al., "Segmental heterogeneity of electrogenic secretions in human ascending colon and rectum," International Journal of Colorectal Disease, vol. 21, no. 4, pp. 357364, 2006.

[24] T. Yajima, R. Inoue, M. Matsumoto, and M. Yajima, "Nonneuronal release of ACh plays a key role in secretory response to luminal propionate in rat colon," Journal of Physiology, vol. 589, no. 4, pp. 953-962, 2011.

[25] K. A. Hubel and L. Russ, "Mechanisms of the secretory response to luminal propionate in rat descending colon in vitro," Journal of the Autonomic Nervous System, vol. 43, no. 3, pp. 219-229, 1993. 
[26] A. M. Harrington, J. M. Hutson, and B. R. Southwell, "Cholinergic neurotransmission and muscarinic receptors in the enteric nervous system," Progress in Histochemistry and Cytochemistry, vol. 44, no. 4, pp. 173-202, 2010.

[27] A. Kuwahara, X. Y. Tien, L. J. Wallace, and H. J. Cooke, "Cholinergic receptors mediating secretion in guinea pig colon," Journal of Pharmacology and Experimental Therapeutics, vol. 242, no. 2, pp. 600-606, 1987.

[28] G. Den Besten, K. Van Eunen, A. K. Groen, K. Venema, D.-J. Reijngoud, and B. M. Bakker, "The role of short-chain fatty acids in the interplay between diet, gut microbiota, and host energy metabolism," Journal of Lipid Research, vol. 54, no. 9, pp. 23252340, 2013.

[29] M. Behrens and W. Meyerhof, "Gustatory and extragustatory functions of mammalian taste receptors," Physiology and Behavior, vol. 105, no. 1, pp. 4-13, 2011.

[30] C. Sternini, L. Anselmi, and E. Rozengurt, "Enteroendocrine cells: a site of "taste" in gastrointestinal chemosensing," Current Opinion in Endocrinology, Diabetes and Obesity, vol. 15, no. 1, pp. 73-78, 2008.

[31] K. L. Mueller, M. A. Hoon, I. Erlenbach, J. Chandrashekar, C. S. Zuker, and N. J. P. Ryba, "The receptors and coding logic for bitter taste," Nature, vol. 434, no. 7030, pp. 225-229, 2005.

[32] E. Adler, M. A. Hoon, K. L. Mueller, J. Chandrashekar, N. J. P. Ryba, and C. S. Zuker, "A novel family of mammalian taste receptors," Cell, vol. 100, no. 6, pp. 693-702, 2000.

[33] Y. Go, Y. Satta, O. Takenaka, and N. Takahata, "Lineage-specific loss of function of bitter taste receptor genes in humans and nonhuman primates," Genetics, vol. 170, no. 1, pp. 313-326, 2005.

[34] H. Matsunami, J.-P. Montmayeur, and L. B. Buck, "A family of candidate taste receptors in human and mouse," Nature, vol. 404, no. 6778, pp. 601-604, 2000.

[35] P. Shi, J. Zhang, H. Yang, and Y.-P. Zhang, "Adaptive diversification of bitter taste receptor genes in mammalian evolution," Molecular Biology and Evolution, vol. 20, no. 5, pp. 805-814, 2003.

[36] S. K. McLaughlin, P. J. McKinnon, and R. F. Margolskee, "Gustducin is a taste-cell-specific G protein closely related to the transducins," Nature, vol. 357, no. 6379, pp. 563-569, 1992.

[37] K. Sutherland, R. L. Young, N. J. Cooper, M. Horowitz, and L. A. Blackshaw, "Phenotypic characterization of taste cells of the mouse small intestine," The American Journal of PhysiologyGastrointestinal and Liver Physiology, vol. 292, no. 5, pp. G1420G1428, 2007.

[38] M. C. Chen, S. V. Wu, J. R. Reeve Jr., and E. Rozengurt, "Bitter stimuli induce $\mathrm{Ca}^{2+}$ signaling and CCK release in enteroendocrine STC-1 cells: role of L-type voltage-sensitive $\mathrm{Ca}^{2+}$ channels," The American Journal of Physiology: Cell Physiology, vol. 291, no. 4, pp. C726-C739, 2006.

[39] C. D. Dotson, L. Zhang, H. Xu et al., "Bitter taste receptors influence glucose homeostasis," PLoS ONE, vol. 3, no. 12, Article ID e3974, 2008.

[40] T.-I. Jeon, B. Zhu, J. L. Larson, and T. F. Osborne, "SREBP-2 regulates gut peptide secretion through intestinal bitter taste receptor signaling in mice," Journal of Clinical Investigation, vol. 118, no. 11, pp. 3693-3700, 2008.

[41] S. Prandi, M. Bromke, S. Hübner et al., "A subset of mouse colonic goblet cells expresses the bitter taste receptor Tas2r131," PLoS ONE, vol. 8, no. 12, Article ID e82820, 2013.

[42] Y. S. Kim and S. B. Ho, "Intestinal goblet cells and mucins in health and disease: recent insights and progress," Current Gastroenterology Reports, vol. 12, no. 5, pp. 319-330, 2010.
[43] M. A. McGuckin, S. K. Lindén, P. Sutton, and T. H. Florin, "Mucin dynamics and enteric pathogens," Nature Reviews Microbiology, vol. 9, no. 4, pp. 265-278, 2011.

[44] J. Chandrashekar, K. L. Mueller, M. A. Hoon et al., "T2Rs function as bitter taste receptors," Cell, vol. 100, no. 6, pp. 703-711, 2000.

[45] V. B. Duffy, A. C. Davidson, J. R. Kidd et al., "Bitter receptor gene (TAS2R38), 6-n-propylthiouracil (PROP) bitterness and alcohol intake," Alcoholism: Clinical and Experimental Research, vol. 28, no. 11, pp. 1629-1637, 2004.

[46] T. M. Nelson, S. D. Munger, and J. D. Boughter Jr., "Taste sensitivities to PROP and PTC vary independently in mice," Chemical Senses, vol. 28, no. 8, pp. 695-704, 2003.

[47] R. S. J. Keast and J. Roper, "A complex relationship among chemical concentration, detection threshold, and suprathreshold intensity of bitter compounds," Chemical Senses, vol. 32, no. 3, pp. 245-253, 2007.

[48] M. Diener and W. Rummel, "Distension-induced secretion in the rat colon: mediation by prostaglandins and submucosal neurons," European Journal of Pharmacology, vol. 178, no. 1, pp. 47-57, 1990.

[49] I. I. Singer, D. W. Kawka, S. Schloemann, T. Tessner, T. Riehl, and W. F. Stenson, "Cyclooxygenase 2 is induced colonic epithelial cells in inflammatory bowel disease," Gastroenterology, vol. 115, no. 2, pp. 297-306, 1998.

[50] P. Sharon and W. F. Stenson, "Enhanced synthesis of leukotriene B4 by colonic mucosa in inflammatory bowel disease," Gastroenterology, vol. 86, no. 3, pp. 453-460, 1984.

[51] D. R. Halm and S. T. Halm, "Prostanoids stimulate K secretion and $\mathrm{Cl}$ secretion in guinea pig distal colon via distinct pathways," American Journal of Physiology-Gastrointestinal and Liver Physiology, vol. 281, no. 4, pp. G984-G996, 2001.

[52] F. R. Homaidan, L. Zhao, and R. Burakoff, "Characterization of PGE2 receptors in isolated rabbit colonic crypt cells," The American Journal of Physiology: Gastrointestinal and Liver Physiology, vol. 268, no. 2, pp. G270-G275, 1995.

[53] F. M. Nagengast, M. J. A. L. Grubben, and I. P. Van Munster, "Role of bile acids in colorectal carcinogenesis," European Journal of Cancer A: General Topics, vol. 31, no. 7-8, pp. 10671070, 1995.

[54] T. Braun, P. Voland, L. Kunz, C. Prinz, and M. Gratzl, "Enterochromaffin cells of the human gut: Sensors for spices and odorants," Gastroenterology, vol. 132, no. 5, pp. 1890-1901, 2007.

[55] M. Kidd, I. M. Modlin, B. I. Gustafsson, I. Drozdov, O. Hauso, and R. Pfragner, "Luminal regulation of normal and neoplastic human EC cell serotonin release is mediated by bile salts, amines, tastants, and olfactants," American Journal of Physiology: Gastrointestinal and Liver Physiology, vol. 295, no. 2, pp. G260-G272, 2008.

[56] G. Sanz, C. Schlegel, J.-C. Pernollet, and L. Briand, “Comparison of odorant specificity of two human olfactory receptors from different phylogenetic classes and evidence for antagonism," Chemical Senses, vol. 30, no. 1, pp. 69-80, 2005.

[57] J. Kuzma, M. Nemecek-Marshall, W. H. Pollock, and R. Fall, "Bacteria produce the volatile hydrocarbon isoprene," Current Microbiology, vol. 30, no. 2, pp. 97-103, 1995.

[58] S. Herz, J. Wungsintaweekul, C. A. Schuhr et al., "Biosynthesis of terpenoids: YgbB protein converts 4-diphosphocytidyl-2Cmethyl-D-erythritol 2-phosphate to 2C-methyl-D-erythritol 2,4- cyclodiphosphate," Proceedings of the National Academy of Sciences of the United States of America, vol. 97, no. 6, pp. 24862490, 2000. 
[59] C. E. Garner, S. Smith, B. De Lacy Costello et al., "Volatile organic compounds from feces and their potential for diagnosis of gastrointestinal disease," The FASEB Journal, vol. 21, no. 8, pp. 1675-1688, 2007.

[60] D. A. Karlin, A. J. Mastromarino, R. D. Jones, J. R. Stroehlein, and O. Lorentz, "Fecal skatole and indole and breath methane and hydrogen in patients with large bowel polyps or cancer," Journal of Cancer Research and Clinical Oncology, vol. 109, no. 2, pp. 135-141, 1985.

[61] E. Zuccato, M. Venturi, G. di Leo et al., "Role of bile acids and metabolic activity of colonic bacteria in increased risk of colon cancer after cholecystectomy," Digestive Diseases and Sciences, vol. 38, no. 3, pp. 514-519, 1993.

[62] S. Firestein, "How the olfactory system makes sense of scents," Nature, vol. 413, no. 6852, pp. 211-218, 2001.

[63] N. Fukuda, K. Yomogida, M. Okabe, and K. Touhara, "Functional characterization of a mouse testicular olfactory receptor and its role in chemosensing and in regulation of sperm motility," Journal of Cell Science, vol. 117, part 24, pp. 5835-5845, 2004.

[64] A. Stokes, C. Wakano, M. Koblan-Huberson, C. N. Adra, A. Fleig, and H. Turner, "TRPAl is a substrate for de-ubiquitination by the tumor suppressor CYLD," Cellular Signalling, vol. 18, no. 10, pp. 1584-1594, 2006.

[65] S. P. Lee, M. T. Buber, Q. Yang et al., "Thymol and related alkyl phenols activate the hTRPA1 channel," British Journal of Pharmacology, vol. 153, no. 8, pp. 1739-1749, 2008.

[66] H. Xu, M. Delling, J. C. Jun, and D. E. Clapham, "Oregano, thyme and clove-derived flavors and skin sensitizers activate specific TRP channels," Nature Neuroscience, vol. 9, no. 5, pp. 628-635, 2006.

[67] K. Nozawa, E. Kawabata-Shoda, H. Doihara et al., "TRPA1 regulates gastrointestinal motility through serotonin release from enterochromaffin cells," Proceedings of the National Academy of Sciences of the United States of America, vol. 106, no. 9, pp. 34083413, 2009.

[68] G. Boudry and C. Perrier, "Thyme and cinnamon extracts induce anion secretion in piglet small intestine via cholinergic pathways," Journal of Physiology and Pharmacology, vol. 59, no. 3, pp. 543-552, 2008.

[69] G. M. Story, A. M. Peier, A. J. Reeve et al., "ANKTM1, a TRP-like channel expressed in nociceptive neurons, is activated by cold temperatures," Cell, vol. 112, no. 6, pp. 819-829, 2003.

[70] B. F. Bessac, M. Sivula, C. A. von Hehn, J. Escalera, L. Cohn, and S.-E. Jordt, "TRPA1 is a major oxidant sensor in murine airway sensory neurons," Journal of Clinical Investigation, vol. 118, no. 5, pp. 1899-1910, 2008.

[71] T. Streng, H. E. Axelsson, P. Hedlund et al., "Distribution and function of the hydrogen sulfide-sensitive TRPA1 ion channel in rat urinary bladder," European Journal of Urology, vol. 53, no. 2, pp. 391-400, 2008.

[72] R. Atoyan, D. Shander, and N. V. Botchkareva, "Non-neuronal expression of transient receptor potential type A1 (TRPA1) in human skin," Journal of Investigative Dermatology, vol. 129, no. 9, pp. 2312-2315, 2009.

[73] D. A. Andersson, C. Gentry, S. Moss, and S. Bevan, “Transient receptor potential $\mathrm{Al}$ is a sensory receptor for multiple products of oxidative stress," Journal of Neuroscience, vol. 28, no. 10, pp. 2485-2494, 2008.

[74] M. Bandell, G. M. Story, S. W. Hwang et al., "Noxious cold ion channel TRPA1 is activated by pungent compounds and bradykinin," Neuron, vol. 41, no. 6, pp. 849-857, 2004.
[75] T. E. Taylor-Clark, B. J. Undem, D. W. MacGlashan Jr., S. Ghatta, M. J. Carr, and M. A. McAlexander, "Prostaglandin-induced activation of nociceptive neurons via direct interaction with transient receptor potential A1 (TRPA1)," Molecular Pharmacology, vol. 73, no. 2, pp. 274-281, 2008.

[76] H. Doihara, K. Nozawa, E. Kawabata-Shoda, R. Kojima, T. Yokoyama, and H. Ito, "Molecular cloning and characterization of dog TRPA1 and AITC stimulate the gastrointestinal motility through TRPA1 in conscious dogs," European Journal of Pharmacology, vol. 617, no. 1-3, pp. 124-129, 2009.

[77] A. Penuelas, K. Tashima, S. Tsuchiya et al., "Contractile effect of TRPA1 receptor agonists in the isolated mouse intestine," European Journal of Pharmacology, vol. 576, no. 1-3, pp. 143150, 2007.

[78] T. Ueda, T. Yamada, S. Ugawa, Y. Ishida, and S. Shimada, "TRPV3, a thermosensitive channel is expressed in mouse distal colon epithelium," Biochemical and Biophysical Research Communications, vol. 383, no. 1, pp. 130-134, 2009.

[79] M. Diener, R. J. Bridges, S. F. Knobloch, and W. Rummel, "Neuronally mediated and direct effects of prostaglandins on ion transport in rat colon descendens," Naunyn-Schmiedeberg's Archives of Pharmacology, vol. 337, no. 1, pp. 74-78, 1988.

[80] A. S. Mosa, M. B. Hansen, C. M. Tilotta, and N. Bindslev, "EP4 and EP2 receptor subtypes involved in colonic secretion in rat," Basic and Clinical Pharmacology and Toxicology, vol. 103, no. 3, pp. 214-221, 2008.

[81] M. Lejeune, P. Leung, P. L. Beck, and K. Chadee, "Role of EP4 receptor and prostaglandin transporter in prostaglandin E 2-induced alteration in colonic epithelial barrier integrity," The American Journal of Physiology-Gastrointestinal and Liver Physiology, vol. 299, no. 5, pp. G1097-G1105, 2010.

[82] S.-E. Jordt, D. M. Bautista, H.-H. Chuang et al., "Mustard oils and cannabinoids excite sensory nerve fibres through the TRP channel ANKTM1," Nature, vol. 427, no. 6971, pp. 260-265, 2004.

[83] D. P. Poole, J. C. Pelayo, F. Cattaruzza et al., "Transient receptor potential ankyrin 1 is expressed by inhibitory motoneurons of the mouse intestine," Gastroenterology, vol. 141, no. 2, pp. 565e4, 2011. 

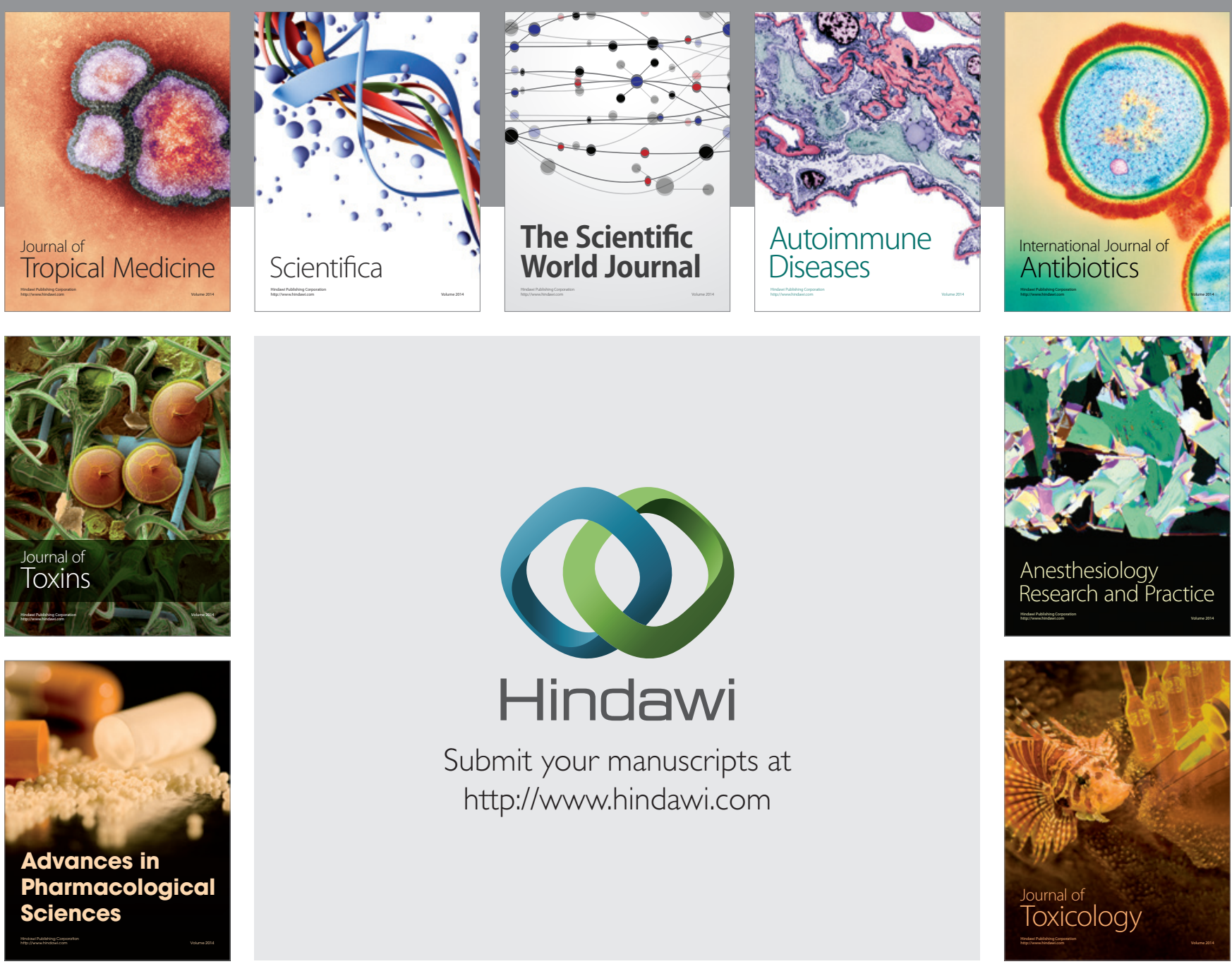

\section{Hindawi}

Submit your manuscripts at

http://www.hindawi.com
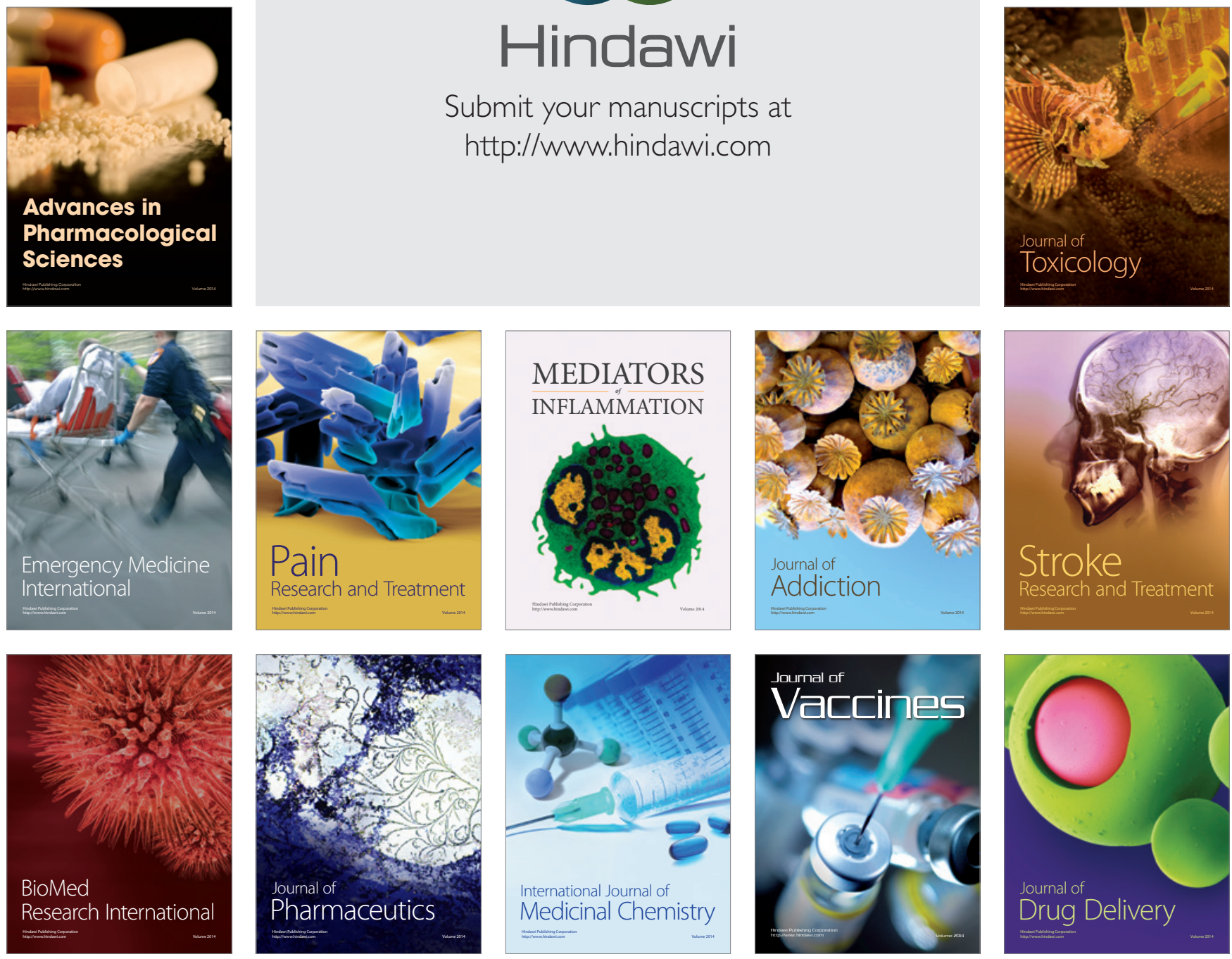